\title{
As bandas onduladas e sua influência na evolução do relevo em São Pedro-SP (Brasil) ${ }^{*}$
}

\author{
Déborah de Oliveira $^{* *}$
}

\section{Resumo}

Este trabalho tem o objetivo de apresentar algumas discussões sobre a pedogênese e a morfogênese em São Pedro-SP. Algumas evidências macro e micromorfológicas sugerem que bandas onduladas encontradas no sistema pedológico Neossolos Quartzarênicos/Argissolos são responsáveis pela evolução morfogenética da borda do glacis de São Pedro.

Palavras-chave: Glacis de São Pedro; Bandas onduladas; Sistema pedológico Neossolo Quartzarênico /Argissolo.

Lamellaes and their influence on the relief evolution in São PedroSP (Brazil)

\begin{abstract}
This paper has the objective of presenting some discussions about pedogenesis and morphogenesis in São Pedro-SP. Some macro and micromorphologic evidences suggest that lamellae in the pedologic system Quartzipsamments/Argissols are responsable for the morphogenetic evolution at the edge of São Pedro glacis.

Key words: São Pedro glacis; Lamellae; Pedologic system Quartzipsamments/Argissols.

* Pesquisa financiada pela FAPESP (Fundação de Amparo à Pesquisa do Estado de São Paulo).

** Professora do Departamento de Geografia da Universidade de São Paulo (USP) (debolive@usp.br).
\end{abstract}

Geosul, Florianópolis, v. 24, n. 47, p 161-186, jan./jun. 2009 
OLIVEIRA, D. de. As bandas onduladas e sua influência na evolução do...

\section{Introdução e objetivos}

O objetivo principal deste trabalho é caracterizar as organizações macro e micromorfológicas de uma topossequência representativa do sistema pedológico Neossolo Quartzarênico com bandas onduladas/Argissolo/Neossolo Litólico, evidenciando-se as estruturas pedológicas presentes nessas duas escalas e suas interrelações, no sentido de fornecer subsídios para a compreensão da dinâmica pedogenética. Esse sistema pedológico ocorre na zona de transição entre o setor mais preservado e o mais dissecado do glacis de São Pedro, SP-Brasil (OLIVEIRA, 1997).

\section{Área de estudo}

\section{Localização}

Na Depressão Periférica Paulista, próxima ao contato com o Planalto Ocidental, no município de São Pedro-Estado de São Paulo-Brasil, na periferia da Serra de São Pedro.

A vertente estudada encontra-se na zona de transição do glacis mais preservado para o mais dissecado, no interflúvio entre os ribeirões do Meio e Samambaia, na margem esquerda da Bacia do Córrego do Retiro, alto curso do ribeirão homônimo, em São Pedro-SP (FIGURA 1). 
OLIVEIRA, D. de. As bandas onduladas e sua influência na evolução do...

Figura 1: Localização da área de estudo
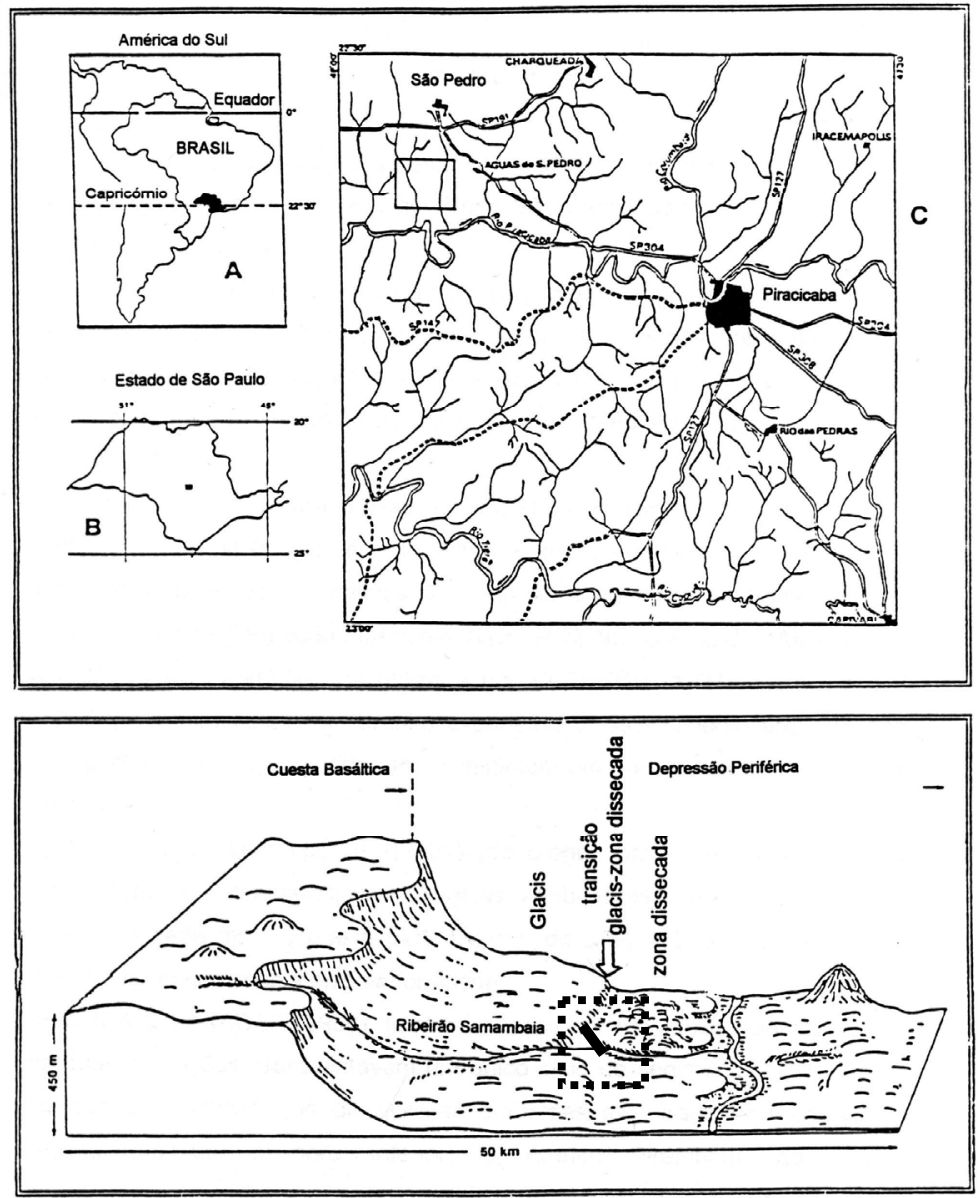

região de estudo

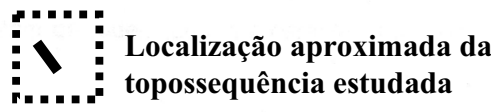

FONTE: OLIVEIRA \& van den BERG, 1992 (adaptado por OLIVEIRA, D. de, 1996) 
OLIVEIRA, D. de. As bandas onduladas e sua influência na evolução do...

\section{Geologia}

O embasamento geológico da área de estudo corresponde à Formação Pirambóia, de origem sedimentar, pertencente ao Grupo São Bento (Mesozóico) na Bacia Sedimentar do Paraná.

A Formação Pirambóia compreende um conjunto de depósitos essencialmente arenosos, de ambiente fluvial, que repousa em discordância sobre os arenitos do Permiano; sua espessura máxima é superior a $300 \mathrm{~m}$ no Estado de São Paulo e sua idade vai do Triássico Inferior ou Médio ao Jurássico. (WU \& SOARES, 1974)

\section{Geomorfologia e solos}

A região de São Pedro-SP situa-se na província geomorfológica da Depressão Periférica Paulista (ALMEIDA, 1964), próximo ao limite com a escarpa das Cuestas Basálticas, cujo topo marca o início do Planalto Ocidental. Apresenta vários compartimentos geomorfológicos locais que se distribuem de norte a sul desde a cuesta, localmente denominada de Serra de São Pedro e de Itaqueri, até o vale do rio Piracicaba. São eles: reverso da cuesta, escarpa, amplos interflúvios ou glacis, zona dissecada, terraços e várzea. (QUEIROZ NETO \& JOURNAUX,1978; COUTARD et al,1978)

O glacis de São Pedro está disposto como uma superfície orientada de Norte a Sul, onde a dissecação que se seguiu à sua esculturação deu origem a interflúvios alongados e paralelos entre si, que se estreitam progressivamente, tornando-se mais dissecados rumo à várzea do rio Piracicaba.

O conjunto do glacis pode ser dividido em três setores, conforme Oliveira (1992) e como mostra na FIGURA 1 (bloco diagrama): o menos dissecado (amplos interflúvios), a transição para o mais dissecado e o mais dissecado (interflúvios estreitos, alongados e morrotes).

A área de estudo propriamente dita situa-se na passagem dos amplos interflúvios (glacis preservado) para a zona dissecada e 
OLIVEIRA, D. de. As bandas onduladas e sua influência na evolução do...

aqui foi denominada de zona de transição glacis-zona dissecada (FIGURA 2).

Figura 2: Hipsometria da área de estudo.

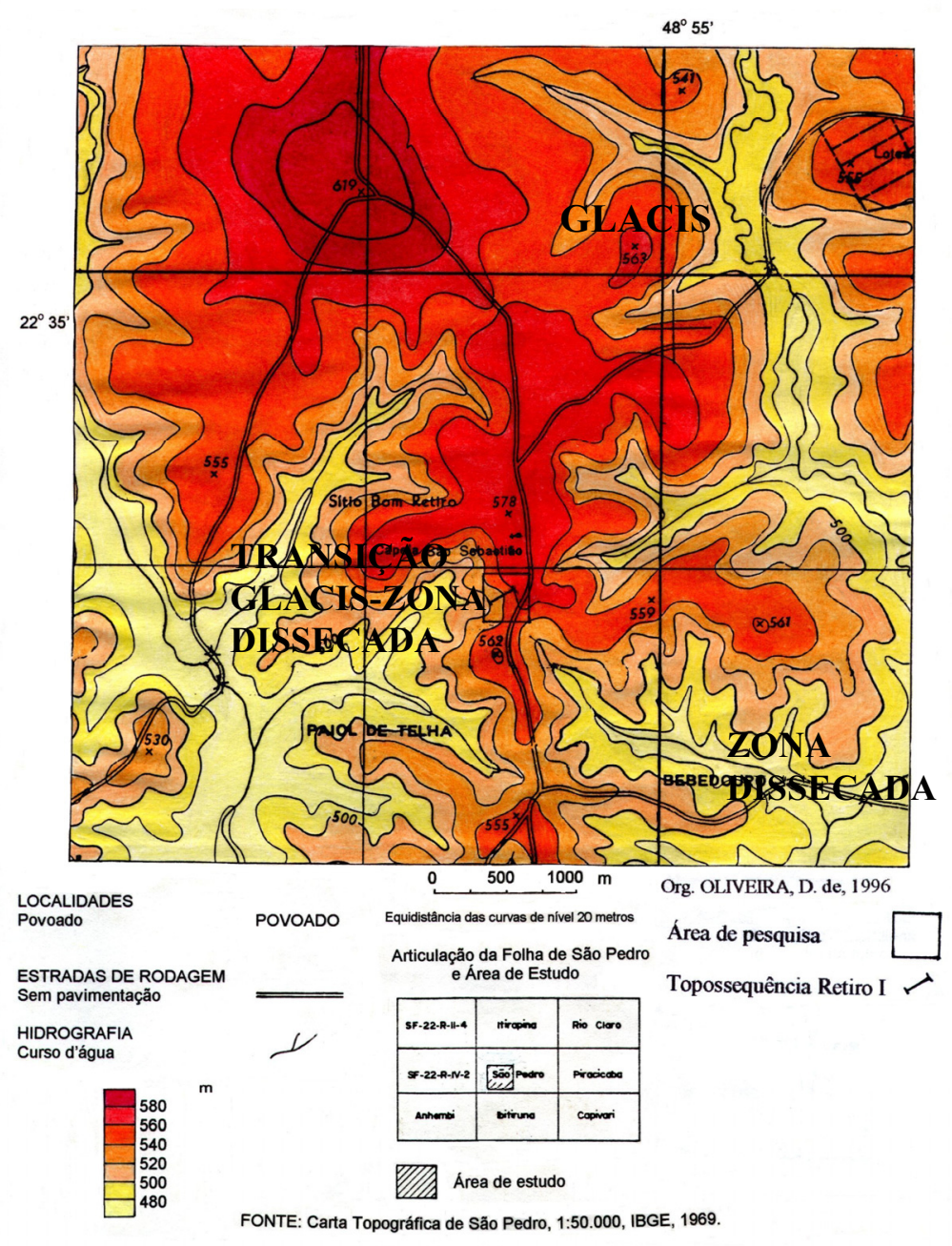


OLIVEIRA, D. de. As bandas onduladas e sua influência na evolução do...

\begin{tabular}{l}
\hline Os compartimentos presentes na área de estudo \\
caracterizam-se como a seguir: \\
-o glacis (preservado): corresponde a uma superfície
\end{tabular} inclinada e muito suave que se estende do sopé da escarpa e se estende por 6 a $7 \mathrm{~km}$ em direção ao rio Piracicaba, decrescendo de $620 \mathrm{~m}$ altitude até atingir cerca de $540 \mathrm{~m}$ na transição deste para a zona dissecada e com declividades que aumentam da ordem de 3 para 6\% (CAPELLARI, 1996).

Nesse mesmo sentido corta a série de arenitos e siltitos da formação Pirambóia, é recortado por poucos eixos de drenagem (os ribeirões Vermelho, do Meio e Samambaia) em largos interflúvios dispostos na direção Norte-Sul, com relevo suave e pouco dissecado e acha-se recoberto por uma espessa formação arenosa, os Neossolos Quartzarênicos, conforme o já exposto.

Os ribeirões Vermelho, do Meio e Samambaia, seus principais eixos de drenagem, em seu curso médio recortam os largos interflúvios desenvolvendo padrão subretangular, de baixa densidade e pouca energia de dissecação. Neste compartimento dominam os Neossolos Quartzarênicos. São solos álicos, essencialmente quartzosos, desenvolvidos sobre material de origem arenoso e relacionados com os arenitos da Formação Pirambóia. Sua fração areia é igual ou superior a $70 \%$, onde a areia fina é dominante (mais de 55\%) e a fração argila inferior a $15 \%$. Os minerais primários intemperizáveis são virtualmente inexistentes ou pouco relevantes. Apresentam horizonte A fraco, moderado ou até proeminente. São, em geral, muito espessos e de cor brunoavermelhada (5YR 4/3,4/2) a bruno-escura (7,5YR 4/3,4/4).

-a transição glacis-zona dissecada: a passagem do glacis para a zona dissecada se dá aproximadamente entre as altitudes de 540 e 500m. É marcada por declives mais fortes, da ordem de $20 \%$ (CAPELLARI, 1996), onde o arenito Pirambóia aflora nas vertentes, formando cornijas. Essa transição é marcada por vários nichos de nascente, com rios de $1^{\mathrm{a}}$ ordem intermitentes e vales em "V" fechado. Nesta faixa os interflúvios são muito recortados até 
OLIVEIRA, D. de. As bandas onduladas e sua influência na evolução do...

tornarem-se alongados e estreitos em direção à zona mais dissecada ao sul.

O perfil da vertente estudada localiza-se nesta transição, é convexo no topo e côncavo a partir da ruptura de declive, com amplitude máxima das altitudes de $555 \mathrm{~m}$ no topo a $520 \mathrm{~m}$ até a ruptura de declive e desta até $465 \mathrm{~m}$ no eixo de drenagem (Córrego do Retiro), trecho este pertencente à zona dissecada. Próximo à zona dissecada no interflúvio dos Ribeirões do Meio-Samambaia a espessura dos Neossolos Quartzarênicos diminui e ocorre a sua substituição progressiva por Argissolo Vermelho-Amarelo, marcada pela presença de horizonte subsuperficial arenoso e espesso, com bandas onduladas intercaladas com lentes arenosas eluviadas, passando, na base dos perfis a um horizonte profundo similar a Neossolo Quartzarênico. É nessa passagem lateral de Neossolo Quartzarênico para Argissolo Vermelho-Amarelo que se encontra o sistema pedológico estudado. (OLIVEIRA, 1992)

As bandas onduladas são centimétricas a milimétricas, avermelhadas, contendo mais argila, contrastadas, subhorizontais, relativamente paralelas entre si e freqüentemente anastomosadas, coalescentes e mais espessas na base dos perfis. $\mathrm{O}$ horizonte com bandas onduladas encontra-se situado acima de um horizonte arenoso, sem bandas, profundo e com características similares aos Neossolos Quartzarênicos do setor norte.

-a zona dissecada: encontra-se entre 500 e $460 \mathrm{~m}$ de altitude. Apresenta interflúvios estreitos e sinuosos, que variam de convexos a retilíneos, com declividades da ordem de 12 a $20 \%$ (CAPELLARI, 1996). A densidade de drenagem é elevada, os vales são profundamente encaixados e em "V"; os canais possuem padrão dendrítico, a drenagem é de média densidade e nas vertentes de declividade mais forte, o arenito Pirambóia aflora formando cornijas, onde é comum a ocorrência de ravinamentos relacionados à circulação hídrica superficial e subsuperficial. Esta zona caracteriza-se pela presença generalizada de solos Argissolos Vermelho-Amarelos que se caracterizam pela forte diferenciação vertical, resultante da presença de horizonte A fraco ou moderado, 
OLIVEIRA, D. de. As bandas onduladas e sua influência na evolução do...

de textura arenosa seguido em profundidade por um horizonte $\mathrm{E}$ (eluvial) também arenoso sobreposto a um horizonte Bt de textura média, estrutura em blocos, cerosidade moderada. São solos tanto álicos como distróficos e se desenvolvem sobre os arenitos da formação Pirambóia.

\section{Algumas interpretações sobre a origem das bandas onduladas}

Suguio \& Coimbra (1976) afirmam que o problema da gênese das bandas onduladas é ainda bastante controvertido. Segundo esses autores, a existência de bandas onduladas salientes intercaladas por partes reentrantes no horizonte A é explicável pelas pequenas diferenças em composição dos teores de argila, $\mathrm{CaCo}_{3}$, óxido de ferro etc. Segundo esses autores, o aparecimento dessas faixas alternantes é explicável por pequenas descontinuidades litológicas pré-existentes. Neste caso, a atuação dos processos pedogenéticos foi apenas realçada.

Dijkerman et al (1967) já ressaltavam que os solos com bandas onduladas não são somente formados por acumulação de argila nas bandas, mas em diferentes casos sugerem além da iluviação de argila, a formação de argila in situ, a ação do gelo e a sedimentação durante a formação do material de origem. Segundo eles, vários pesquisadores têm explicado a acumulação de argila nas bandas onduladas por processos rítmicos, pela ação da floculação dos óxidos de ferro livre ou carbonatos nas partes baixas do perfil, por algum tipo de precipitação química periódica do ferro, com subsequente floculação da argila, por evapotranspiração da frente úmida ou por peneiramento em camadas de porosidade fina. Para esses autores, o fluxo de água carrega partículas em suspensão pela ação da gravidade e peneiramento formando uma banda incipiente que acaba sendo uma barreira para o movimento da água descendente, dado pelo entupimento dos poros de baixo para cima e, subconsequentemente, acarretando o aumento da espessura da banda. Deste modo, Rawlling (2000), ressalta que as bandas onduladas aparecem somente em solos arenosos e formam- 
OLIVEIRA, D. de. As bandas onduladas e sua influência na evolução do...

se rapidamente e simultaneamente, caracterizando-se como um tipo de horizonte $\mathrm{Bt}$ dos solos.

Bond (1986), reproduz em laboratório a formação das bandas onduladas por processos de iluviação e a subsequente deposição de argila, concluindo que: 1) as bandas são muito semelhantes às encontradas em campo; 2) a dispersão da argila e sua deposição ocorrem por obstrução dos poros finos ou quando se excede o máximo de concentração de argila em suspensão; 3)a formação das bandas ocorre simultaneamente ao longo do perfil; 4) o tempo para a formação das bandas deve ser curto; 5) a velocidade de transporte do material deve ser curta; 6) uma baixa porcentagem de argila $(<1 \%)$ já pode ter efeito nos solos arenosos.

Os cutãs são as feições pedológicas mais comuns nas bandas onduladas e consistem em concentrações plásmicas (que são os cutãs formados por iluviação e difusão de plasma) ou separações plásmicas (que são os cutãs formados por modificações ou rearranjos in situ) associadas às superfícies naturais do solo, às paredes dos torrões, dos grãos de esqueleto e às paredes dos poros. Para se saber a origem dos cutãs é necessário distinguir algumas características como: natureza do material, nitidez dos limites, orientação, distribuição, grau de separação (contraste) em relação ao fundo matricial. (BREWER, 1964)

Assim, Ruellan \& Dosso (1993) sintetisaram as interpretações possíveis sobre a origem das bandas onduladas, como sendo de dois tipos:

-de acumulação: devido a migração vertical e lateral de argila;

-de degradação e lessivagem de partículas argilosas: as bandas são residuais do empobrecimento em argila de um horizonte argiloso. Esses autores ainda sintetisaram a definição das bandas onduladas como camadas de espessura milimétrica a centimétrica, mais ricas em argila, ferro ou matéria orgânica. Essas camadas, geralmente horizontais, são sempre onduladas, com ondulações mais ou menos acentuadas. 
OLIVEIRA, D. de. As bandas onduladas e sua influência na evolução do...

\section{Metodologia}

O trabalho adotou a metodologia da Análise Estrutural da Cobertura Pedológica, que consiste na análise bidimensional da cobertura pedológica em campo (BOULET et al, 1982 a. b) e sua representação cartográfica tridimensional no plano (BOULET et al, 1982 c).

Os perfis de solo foram descritos conforme Lemos \& Santos (1982), com maior detalhe para as transições e feições pedológicas.

As descrições das lâminas delgadas sob microscópio óptico polarizante seguiu a terminologia de Stoops \& Jongerius (1975) para as estruturas de base e Brewer (1964) para a análise do esqueleto e da porosidade.

\section{Resultados obtidos}

\section{A topossequência Retiro I}

A vertente onde se encontra o sistema pedológico estudado apresenta extensão total de $550 \mathrm{~m}$, altitude de 560 a $495 \mathrm{~m}$ e declividade da ordem de $14 \%$ do topo à média vertente e $20 \%$ daí em diante, até o sopé.

A topografia da vertente como um todo é convexa no topo e côncava a partir da ruptura de declive da média vertente, a partir da qual ocorre ravinamento e, para jusante, próximo ao Córrego do Retiro, termina por cornijas com afloramento do arenito.

À montante apresenta uma cobertura arenosa espessa (Neossolo Quartzarênico), vermelho-amarela dominante com volumes de areia lavada na superfície e bandas onduladas na subsuperfície, que passa lateral e verticalmente para a média vertente a uma organização argissólica cada vez mais definida. Para a baixa vertente passa aos Neossolos Litólicos (FIGURA 3). 
OLIVEIRA, D. de. As bandas onduladas e sua influência na evolução do...

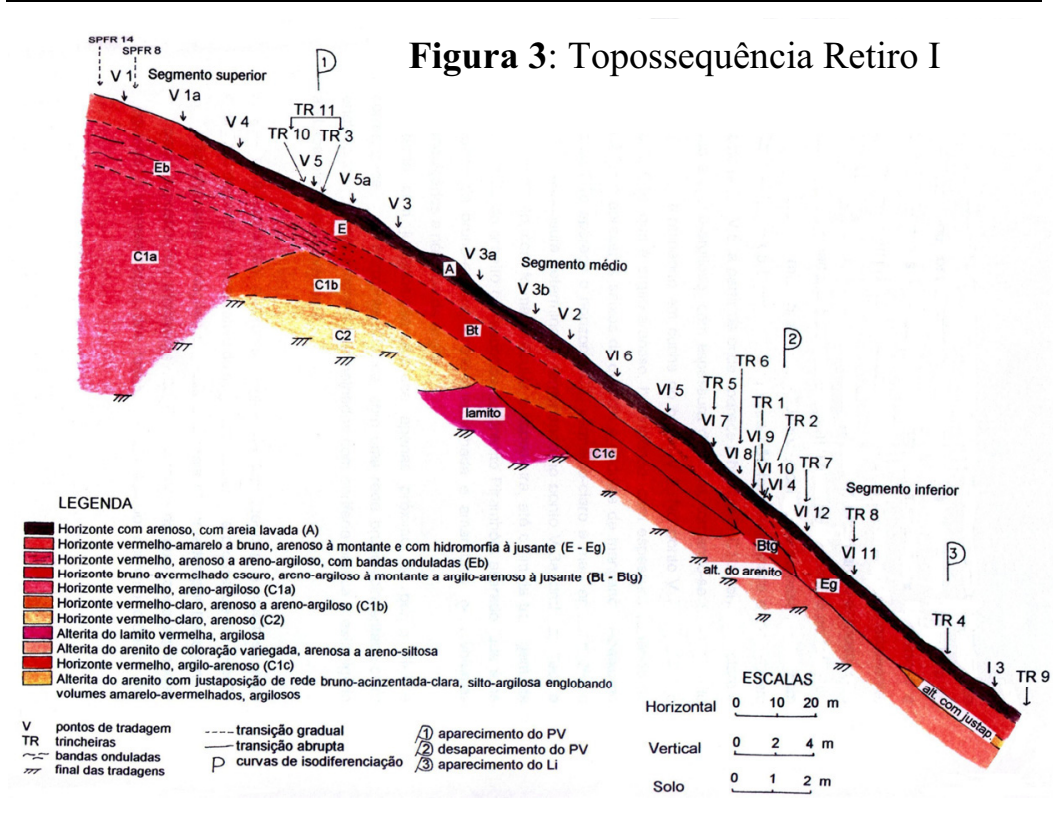

A topossequência Retiro I situa-se no eixo central dessa vertente; apresenta $224 \mathrm{~m}$ de extensão, direção NE-SO e corresponde apenas ao setor superior e médio da vertente, da qual foi excluída a parte do setor inferior.

De forma geral, a topossequência apresenta a seguinte sucessão de horizontes:

$O$ horizonte A (superficial) aparece em quase toda a extensão da vertente, com espessura de aproximadamente $20 \mathrm{~cm}$, variando ao longo da topossequência de 10 a $30 \mathrm{~cm}$; é arenoso com areia lavada. O horizonte E (subsuperficial) é vermelho-amarelo, também arenoso com areia lavada; sua espessura é de $80 \mathrm{~cm}$ no topo da vertente, diminuindo para jusante até o ponto VI 14, onde passa ao Eg, já areno-argiloso e com sinais de hidromorfia.

$\mathrm{O}$ horizonte $\mathrm{Eb}$ (bandas) aparece apenas no topo da vertente $\mathrm{e}$ corresponde ao horizonte vermelho com bandas (Neossolo Quartzarênico do topo) com espessura de $1 \mathrm{~m}$ no ponto V 1. Este passa progressivamente ao horizonte $\mathrm{Bt}$ arenoso a areno-argiloso 
OLIVEIRA, D. de. As bandas onduladas e sua influência na evolução do...

na média vertente, com $60 \mathrm{~cm}$ de espessura aproximadamente, do ponto $\mathrm{V} 4$ até $\mathrm{VI} 7$, onde passa ao Btg, areno-argiloso a argiloarenoso, com rede bruno-avermelhada, até o ponto VI 4, onde termina a cobertura argissólica.

O horizonte Cla é vermelho, areno-argiloso e encontra-se na base do Neossolo Quartzarênico com bandas onduladas do topo; sua espessura não foi determinada e termina em cunha no ponto $\mathrm{V} 5$, a partir de onde aparece o horizonte $\mathrm{Clb}$, vermelho-claro e arenoso a areno-argiloso, com espessura de $1,2 \mathrm{~m}$, tornando-se mais estreito para jusante, terminando em cunha no ponto $\mathrm{V} 2$. No ponto $\mathrm{V} 3 \mathrm{a}$ aparece o horizonte $\mathrm{C} 1 \mathrm{c}$, que é argilo-arenoso, homogêneo, com espessura variando de 1,8 a $2,3 \mathrm{~m}$ e apresenta seixos de quartzo e nódulos de manganês. Abaixo do horizonte $\mathrm{C} 1 \mathrm{~b}$ aparece o horizonte $\mathrm{C} 2$, vermelho-claro e mais arenoso que o $\mathrm{C} 1 \mathrm{~b}$, sem espessura determinada, terminando no ponto $\mathrm{V} 3 \mathrm{a}$, onde aparece a alterita do lamito, com forma lenticular e espessura, até o fim da tradagem, de $3 \mathrm{~m}$. A alterita do arenito corresponde ao arenito Pirambóia alterado, que é de cor variegada bruno-escura, bruno-avermelhada e amarelada, com volumes esbranquiçados e nódulos de argila.

A alterita com justaposição aparece apenas próximo ao ponto III-3 e corresponde a um horizonte bifásico, com uma rede bruno-acinzentada-clara englobando volumes amareloavermelhados com periferia branca e está ligado ao Neossolo Litólico da baixa vertente.

\section{Caracterização macro e micromorfológica do segmento superior da topossequência Retiro I}

Corresponde ao trecho montante da Topossequência, onde predomina o Neossolo Quartzarênico com bandas onduladas.

$\mathrm{Na}$ escala macroscópica, a Neossolo Quartzarênico com bandas onduladas de montante é representativo do trecho entre os pontos V 1 a V 5 e aparece nas trincheiras SPFR 14 E SPFR 8. Apresenta a seguinte sucessão vertical de horizontes, nesse setor:

-o horizonte superficial arenoso (E): espesso $(0-45 \mathrm{~cm})$, de cor bruno-avermelhada (5YR 4/4), não se destacando nitidamente 
OLIVEIRA, D. de. As bandas onduladas e sua influência na evolução do...

um horizonte humífero superior mais escuro; textura muito arenosa no topo, com ligeiro aumento do teor de argila para a base; presença de areia lavada, sobretudo na parte mais superficial; estrutura muito fraca média poliédrica; porosidade tubular e intergranular forte.

-o horizonte subsuperficial arenoso com bandas onduladas $(\mathrm{Eb})$ : espesso $(45-145 \mathrm{~cm})$, diminuindo progressivamente a $115 \mathrm{~cm}$ para jusante (V 5); apresenta-se vermelho (2,5YR 4/6) e caracteriza-se pela presença de um empilhamento composto de numerosas bandas onduladas subhorizontais relativamente paralelas entre si, mais e mais espessas e coalescentes em profundidade, intercaladas por volumes arenosos denominados de interbandas, mais claros, embora progressivamente em profundidade sejam mais avermelhados, menos contrastados com as bandas e menos espessos. Estas bandas são pouco contrastadas quando o solo está úmido e fortemente contrastadas quando seco; caracterizam-se principalmente por uma resistência um pouco maior à faca, uma textura com um pouco mais de argila (arenosa a areno-argilosa); uma porosidade menor e uma intensa atividade biológica; as bandas apresentam de 1 a $3 \mathrm{~cm}$ de espessura quando bem contrastadas, como na parte superior dos perfis e tornamse mais espessas e anastomosadas rumo à base dos perfis. No material interbandas a cor é vermelho-escuro-acinzentado (2,5YR 3/4) e com a lupa de bolso percebe-se a ocorrência de um retículo milimétrico vermelho vivo, contendo domínios de areia quase desprovida de fração argila (areia lavada); apresentam textura arenosa a arenoargilosa constante e volumes milimétricos isolados, similares às bandas; a estrutura passa progressivamente em profundidade de fraca poliédrica nas bandas para maciça com fratura cada vez mais plana nas interbandas.

-o horizonte profundo (C1a): muito espesso $(145-945 \mathrm{~cm}+$ ); vermelho-escuro $(2,5 \mathrm{YR} 4 / 4,4 / 6$ e 4/8); textura arenosa a arenoargilosa com areia lavada; estrutura maciça com fratura ligeiramente conchoidal, localmente com tendência à poliédrica; a porosidade é intergranular bem desenvolvida com alguns poros tubulares que contêm areia lavada. 
OLIVEIRA, D. de. As bandas onduladas e sua influência na evolução do...

A FIGURA 4 a seguir apresenta o desenho das trincheiras desse segmento.

Figura 4: Perfis da passagem lateral das bandas onduladas ao Bt do Neossolo Quartzarênico com bandas onduladas para Argissolo Vermelho-amarelo do segmento superior da Toposseqüência Retiro I

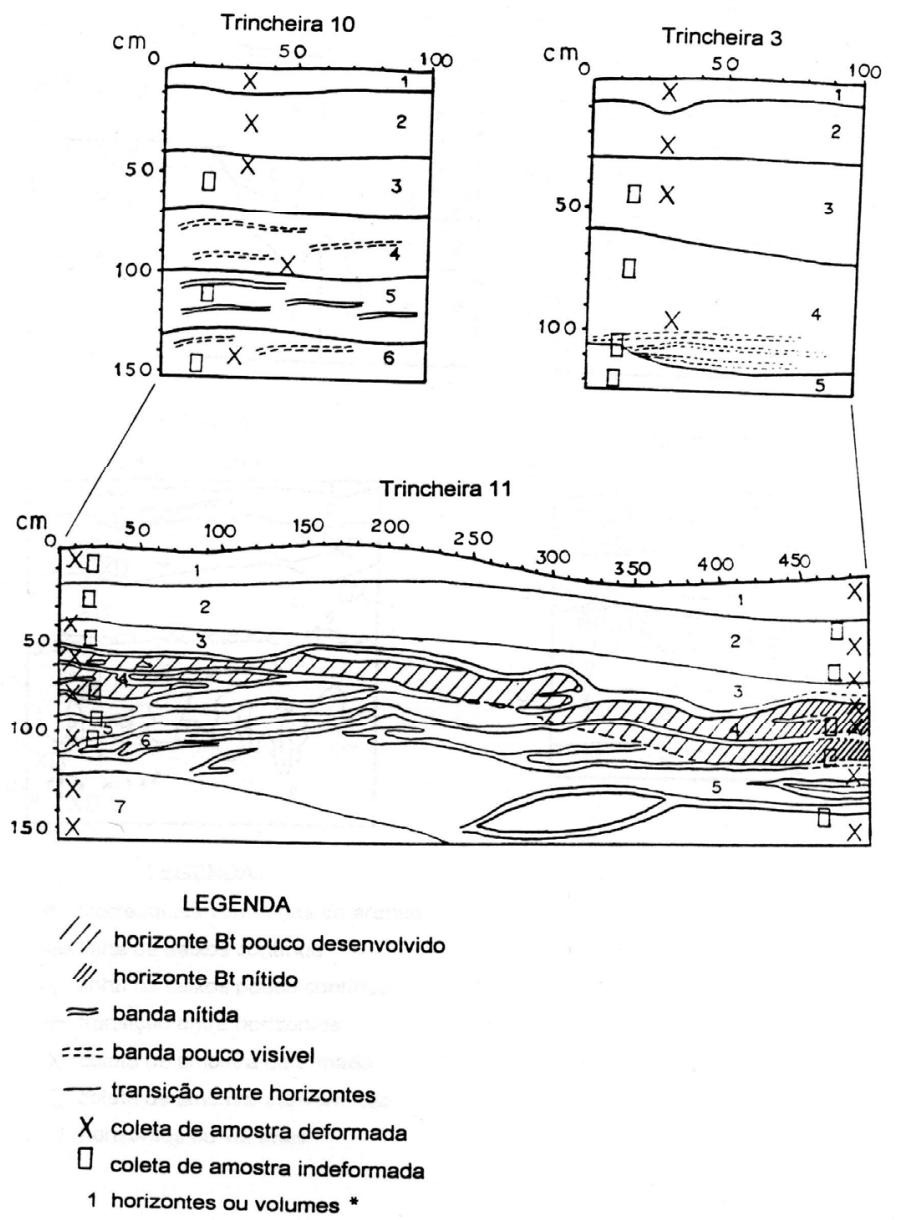


OLIVEIRA, D. de. As bandas onduladas e sua influência na evolução do...

Em síntese, o perfil representativo do segmento superior apresenta um horizonte superficial arenoso (E) com areia lavada sobre um horizonte com bandas onduladas subhorizontais centimétricas $(\mathrm{Eb})$, areno-argilosas intercaladas por um material arenoso a areno-argiloso (interbandas), sendo mais espessas para a base do perfil até passar a um horizonte também arenoso a arenoargiloso (C1a), similar ao material interbandas mais profundo, com estrutura maciça. Fora das bandas o material é muito poroso e permeável, o que confirma a presença de areia lavada nos poros tubulares. As bandas são responsáveis pela diminuição da drenagem vertical por serem menos permeáveis que o material interbandas.

$\mathrm{Na}$ escala microscópica seus horizontes apresentam as seguintes características: o horizonte subsuperficial (E) na TR 3 apresenta fundo matricial pobre em plasma com cerca de $5 \%$, além de cerca de $30 \%$ de poros e $60 \%$ de esqueleto.

Há predomínio de esqueleto ligado por pontes de plasma (estrutura gefúrica) que atingem cerca de $65 \%$ da lâmina e que formam um reticulado geométrico em cujo interior aparecem grãos limpos (estrutura mônica), que correspondem a cerca de 30\% da lâmina, visíveis na FOTOMICROGRAFIA 1; há também pequenos agregados com grãos do esqueleto cimentados por argila (estrutura porfírica) de aproximadamente $1 \mathrm{~mm}$ de diâmetro com esqueleto mais fino em seu interior (5\%), esparsos no fundo matricial da lâmina.

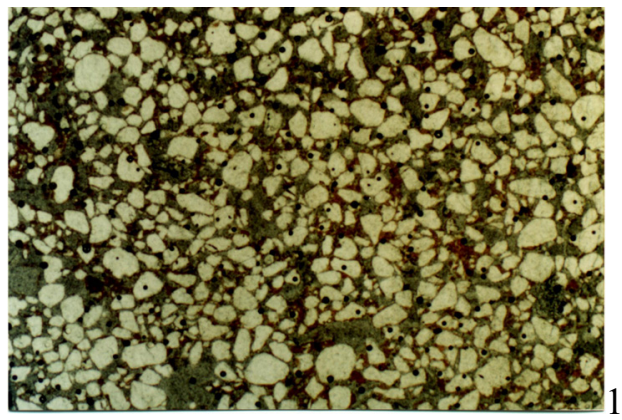

FOTOMICROGRAFIA 1

- L. N. 30X. Aspecto geral do horizonte E da TR 3 com predomínio de esqueleto ligado por pontes de plasma (estrutura gefúrica), formando um reticulado com grãos limpos em seu interior (estrutura mônica). 
OLIVEIRA, D. de. As bandas onduladas e sua influência na evolução do...

O plasma é vermelho-amarelo sob luz natural e opaco sob luz polarizada, provavelmente pela presença da matéria orgânica e do ferro.

A porosidade mais importante é a de empilhamento simples dos grãos $(80 \%)$, seguida pela de cavidades $(20 \%)$. As cavidades são do tipo ortoporos, isto é, suas paredes são formadas pelo arranjo natural do plasma e esqueleto, apresentam formas irregulares no topo do horizonte e arredondadas na base, variam de $0,250 \mathrm{~mm}$ a $1,0 \mathrm{~mm}$ (macroporos muito finos) e são moderadamente comunicantes entre si nas duas dimensões da lâmina, mas são provavelmente comunicantes nas três dimensões.

$\mathrm{O}$ esqueleto é constituido basicamente de grãos de quartzo fino $(0,25$ a $0,125 \mathrm{~mm})$, com cerca de $98 \%$ de quartzo e de $2 \%$ de manganês e/ou carvões. Os grãos são subarredondados, lisos e com distribuição aleatória.

Há ainda a presença de poucos pedotúbulos tubulares simples do tipo granotúbulo com 1,6mm de diâmetro em média, com densidade solta contínua em seu interior, individualização discreta (com limite bem nítido em relação ao fundo matricial); o agente de escavação pode ter sido minhoca ou raízes (não diferenciada na lâmina), a composição do preenchimento é de material proveniente do mesmo horizonte (ortotúbulo).

-o horizonte $\mathrm{E}$ com bandas onduladas (Eb) apresenta dois tipos de organização, uma externa e outra interna às bandas onduladas.

A organização interbandas apresenta um fundo matricial constituído de cerca de $15 \%$ de plasma, $30 \%$ de poros e $55 \%$ de esqueleto.

Predomina uma rede (reticulado) onde os grãos estão cimentados por plasma (estrutura porfírica) e que forma um reticulado mais espesso que no horizonte $\mathrm{E}$ superior, com cerca de $40 \%$ do total, em cujo interior apresenta esqueleto ligado por pontes de plasma (estrutura gefúrica) que atinge $60 \%$ do total e que aparecem na FOTOMICROGRAFIA 2. 
OLIVEIRA, D. de. As bandas onduladas e sua influência na evolução do...

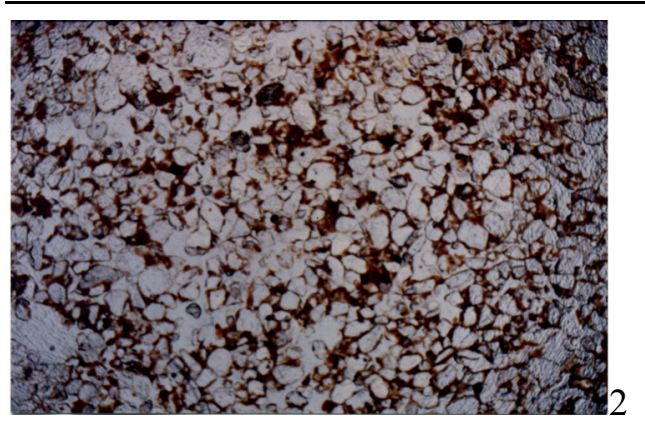

FOTOMICROGRAFIA 2 L.N. 30X. Aspecto geral do material interbandas do horizonte $\mathrm{Eb}$ da trincheira SPFR 8, onde predominam grãos de quartzo cimentados por plasma (estrutura porfírica) e que formam um reticulado com esqueleto ligado por pontes de plasma (estrutura gefúrica) em seu interior.

Cerca de $85 \%$ do total de plasma apresenta-se brunoavermelhado sob luz natural, predominantemente opaco sob luz polarizada e apresenta pápulas visíveis sob aumentos maiores (125x). Os restantes $15 \%$ apresentam-se em agrupamentos de ilhas (mossépico) sob luz polarizada e situam-se preferencialmente na porosidade de empilhamento.

A porosidade é composta basicamente de empilhamento simples dos grãos $(80 \%)$ e de cavidades $(20 \%)$. As cavidades são do tipo ortoporos, com formas irregulares, que variam de $0,5 \mathrm{~mm}$ a 2,0 $\mathrm{mm}$ (macroporos muito finos a médios) e são fracamente comunicantes entre si nas duas dimensões da lâmina, mas são provavelmente comunicantes nas três dimensões.

O esqueleto é constituído de grãos de quartzo fino $(0,25$ a $0,125 \mathrm{~mm}$ ), com cerca de $98 \%$ de quartzo e $2 \%$ de manganês e/ou carvões, os grãos são subarredondados $(85 \%$ do total $)$ a arredondados (15\% do total), lisos e com distribuição aleatória.

A passagem desta organização à banda é marcada por um grande aumento de plasma cimentando os grãos (estrutura porfírica) e por cutãs de poros tanto no limite superior, como nas FOTOMICROGRAFIAS $3 \mathrm{a}$ e $3 \mathrm{~b}$ e também no limite inferior das bandas, como o visto nas FOTOMICROGRAFIAS $4 \mathrm{a}$ e $4 \mathrm{~b}$. 
OLIVEIRA, D. de. As bandas onduladas e sua influência na evolução do...

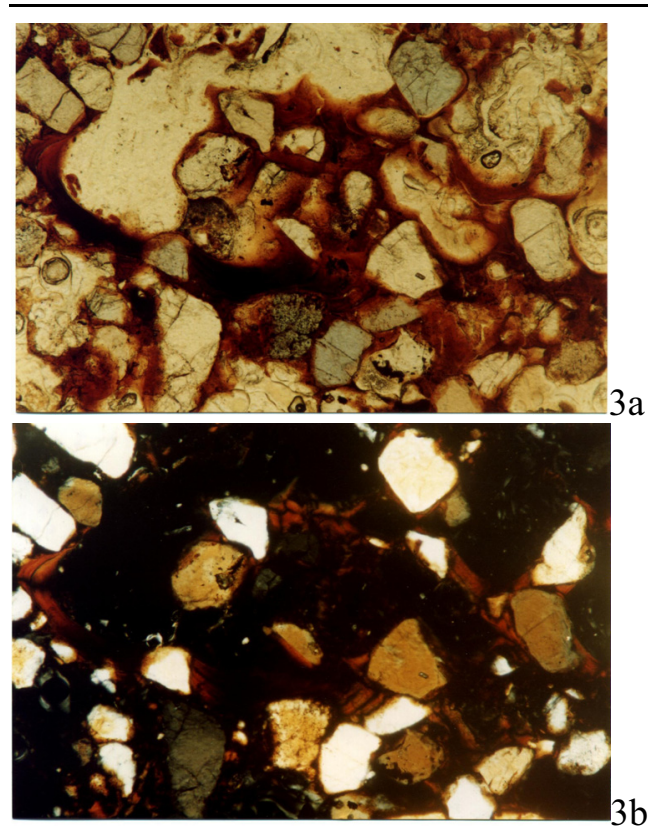

FOTOMICROGRAFIAS 3a e $3 b-$ L.N. e L. P. 80X. Topo de banda ondulada do horizonte $\mathrm{E}$ com bandas onduladas da trincheira SPFR 8, com ferriargilãs iluviais de cavidades, com zonação posterior ao depósito, devido a más condições de drenagem no interior de estrutura porfírica.
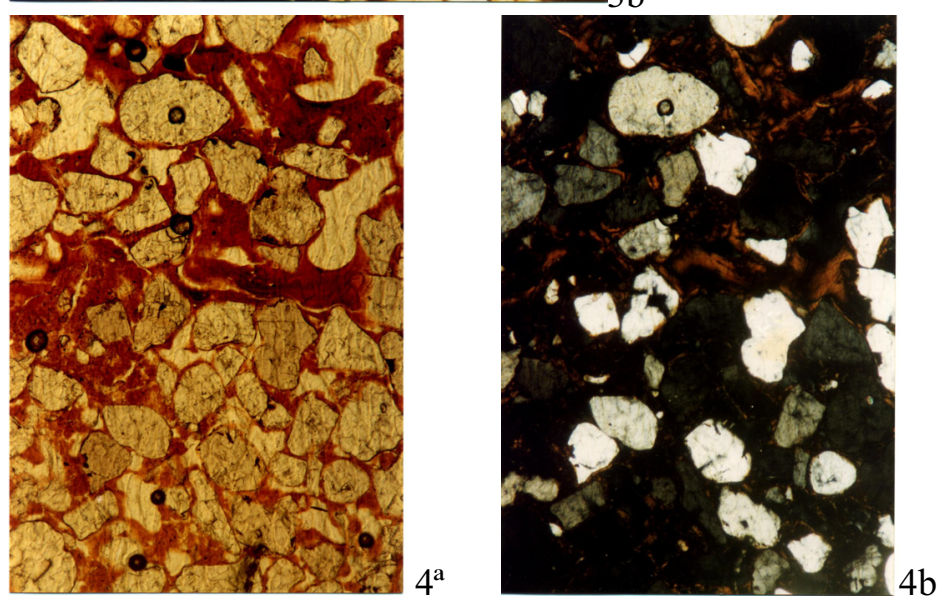

FOTOMICROGRAFIAS 4a e 4b - L.N. e L.P. 80X. Cutãs de iluviação da base da banda ondulada do horizonte Eb da trincheira SPFR 8. Note-se que a passagem é nítida da estrutura com esqueleto cimentado por plasma (estrutura porfírica) da banda para grãos ligados por pontes de plasma (estrutura gefúrica) do material interbandas. 
OLIVEIRA, D. de. As bandas onduladas e sua influência na evolução do...

A organização das bandas apresenta fundo matricial constituído por cerca de $35 \%$ de plasma, $10 \%$ de poros e $55 \%$ de esqueleto.

Apresenta grãos de quartzo envolvidos numa matriz argilosa (estrutura porfírica) predominante e bem mais fechada do que na organização externa às bandas.

O plasma apresenta-se em dois tipos, um não cutânico (15\% do total) e um cutânico de poros e grãos predominante $(85 \%$ do total). Ambos são bruno-avermelhados, mas o plasma não cutânico apresenta separações em agrupamentos de ilhas (mossépico) que lembram pápulas fortemente integradas ao fundo matricial.

A porosidade é constituída basicamente de empilhamento simples dos grãos $(80 \%)$ e de cavidades $(20 \%)$. As cavidades são do tipo metaporos (com as paredes submetidas a pressões), apresentam formas irregulares, variam de $0,5 \mathrm{~mm}$ a $1,0 \mathrm{~mm}$ (macroporos muito finos) e são fracamente comunicantes entre si.

$\mathrm{O}$ esqueleto é semelhante ao externo às bandas.

Os cutãs de poro do topo das bandas são do tipo crescente (de fundo de poro), apresentam contraste forte, limite nítido em relação ao fundo matricial, distribuição laminada (por segregação do ferro), orientação forte, padrão estriado. Os cutãs de grãos são englobados ao fundo matricial, interligando grãos, com distribuição laminada e padrão estriado. Os cutãs do interior das bandas parecem ter sofrido estágios diferentes de acumulação, pois são crescentes, microlaminados, com contraste forte, limite nítido em relação ao fundo matricial e padrão estriado, mas assemelhamse a um empilhamento de vários cutãs interligados e orientados em direções diferentes, como os da FOTOMICROGRAFIA 5. Todas essas características se referem à cutãs de iluviação. 
OLIVEIRA, D. de. As bandas onduladas e sua influência na evolução do...

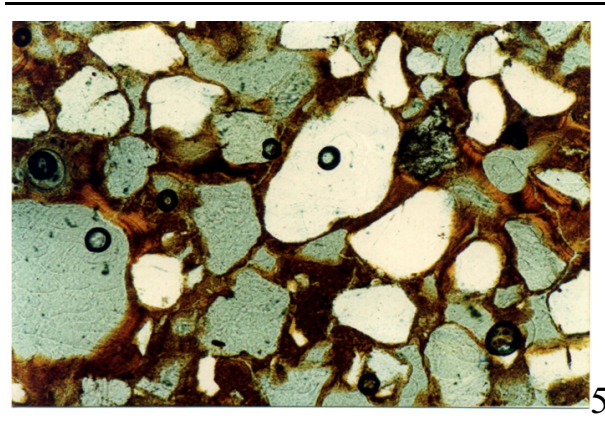

FOTOMICROGRAFIA 5 -

L.P. 125x. Cutãs de iluviação do interior da banda ondulada do horizonte $\mathrm{Eb}$ da trincheira SPFR 8. Notem-se a microlaminação dos cutãs de iluviação orientada em várias direções e algumas microfissuras posteriores ao depósito do plasma.

-o horizonte de profundidade (C1a) apresenta cerca de $15 \%$ de plasma, $35 \%$ de poros e $50 \%$ de esqueleto.

Os grãos estão ligados por pontes de plasma não cutânico (estrutura gefúrica) predominante, com cerca de $90 \%$ e também pequenos agregados de aproximadamente $0,6 \mathrm{~mm}$ que possuem grãos mais finos (silte) em seu interior envolvidos por plasma (estrutura porfírica) que alcançam cerca de $10 \%$ da lâmina.

O plasma é vermelho sob luz natural e sob luz polarizada é opaco e não cutânico, como é possível notar na FOTOMICROGRAFIA 6.

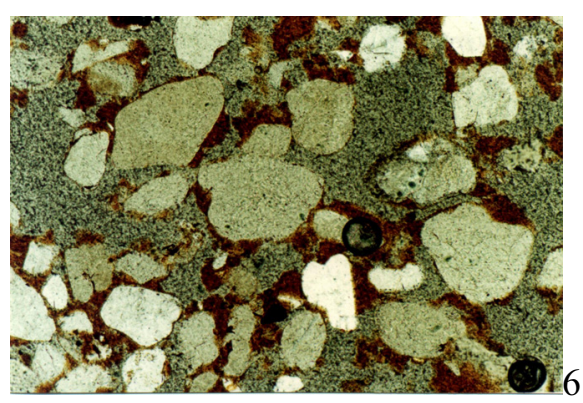

FOTOMICROGRAFIA 6 - L.P. 126X. Aspecto geral do horizonte Cla da trincheira SPFR 14 com esqueleto ligado por pontes de plasma (estrutura gefúrica), forte porosidade de empilhamento e cavitária intercomunicante $\mathrm{e}$ plasma opaco.

A porosidade predominante é a de empilhamento simples dos grãos $(95 \%)$, com contribuição de poucas cavidades $(5 \%)$, que variam de $0,5 \mathrm{~mm}$ a $2,0 \mathrm{~mm}$ (macroporos muito finos a grosseiros, predominando os muito finos), são do tipo ortoporos, arredondados e fracamente comunicantes entre si. 
OLIVEIRA, D. de. As bandas onduladas e sua influência na evolução do...

O esqueleto é constituído de grãos de quartzo fino $(0,25 \mathrm{a}$ $0,125 \mathrm{~mm}$ ), com $97 \%$ de quartzo e $3 \%$ de manganês e/ou carvões. Os grãos são subarredondados, lisos e com distribuição aleatória.

Em síntese, o segmento superior mostra um horizonte E pobre em plasma (cerca de 5\%), com predomínio de esqueleto ligado por pontes de plasma (estrutura gefúrica), que forma um reticulado com grãos sem plasma no interior dos retículos (estrutura mônica). A porosidade de empilhamento simples dos grãos é a mais importante, sendo que esses grãos são subarredondados e lisos em todo o perfil. $\mathrm{O}$ horizonte subsuperficial $\mathrm{Eb}$ (bandas onduladas) apresenta cerca de $15 \%$ de plasma, com uma organização onde os grãos estão cimentados por plasma (estrutura porfírica), formando também um reticulado que apresenta pápulas que podem corresponder a restos de bandas em cujo interior há esqueleto ligado por pontes de plasma (estrutura gefúrica); há presença de cavidades. As bandas onduladas apresentam cerca de $35 \%$ de plasma, com grãos de quartzo envolvidos numa matriz argilosa (estrutura porfírica), com muitos cutãs de poros e de grãos associados a iluviação; há presença de cavidades. O horizonte de profundidade (Cla) apresenta cerca de $15 \%$ de plasma e esqueleto ligado por pontes de plasma (estrutura gefúrica); a porosidade mais importante é a de empilhamento simples dos grãos e há poucas cavidades.

A transição para o segmento médio se faz pela passagem do horizonte $\mathrm{Eb}$ (bandas onduladas) para o horizonte Bt lateral e progressivamente. Neste trecho, as bandas onduladas do $\mathrm{Eb}$ aparecem associadas ao $\mathrm{Bt}$, tanto na sua superfície e base, como no interior deste horizonte. A partir daí, o horizonte Bt torna-se mais desenvolvido e estruturado no rumo jusante, caracterizando um solo Argissolo.

A FIGURA 4 mostra as trincheiras TR 10, TR 11 e TR 3, representativas da passagem do Neossolo Quartzarênico com bandas onduladas do segmento superior para o Argissolo do segmento médio. Tanto na TR10, como na TR3, as bandas pouco nítidas aparecem dentro do horizonte Bt. A TR11, que apresenta um detalhamento maior em relação às outras duas, mostra que o Bt 
OLIVEIRA, D. de. As bandas onduladas e sua influência na evolução do...

aparece para jusante entre as bandas de superfície do Neossolo Quartzarênico, tornando-se cada vez mais nítido e mais espesso ao longo dessa trincheira. As bandas tornam-se cada vez menos nítidas dentro do $\mathrm{Bt}$, que se desenvolve para jusante.

\section{Síntese da macro e micromorfologia do segmento superior da topossequência Retiro I}

$\mathrm{O}$ que se percebe de modo geral, no que se refere à macromorfologia é que:

1- $\mathrm{O}$ horizonte $\mathrm{Eb}$ (bandas onduladas) apresenta um material interbandas mais arenoso no topo do perfil e menos arenoso para a base, onde as bandas se tornam cada vez menos contrastadas nesse sentido;

2- O horizonte Bt inicia-se à montante (TR10, TR 3 e TR11) por um espessamento e coalescência de bandas onduladas, que aparecem acima, no seu interior e abaixo deste e torna-se cada vez mais estruturado para jusante.

$\mathrm{O}$ resultado das observações micromofológicas, de modo geral, mostram que:

1- As bandas onduladas do horizonte Eb apresentam aumento de plasma em relação aos volumes interbandas do mesmo horizonte, ao $\mathrm{E}$ e ao $\mathrm{Cla}$, fazendo com que as estruturas de base gefúricas no volume interbandas passem a porfíricas nas bandas e no Bt;

2- A porosidade de empilhamento do volume interbandas e horizonte Cla passa de uma porosidade de empilhamento a uma macroporosidade cavitária irregular e de canais nas bandas e no $\mathrm{Bt}$, sedes da acumulação de argila por iluviação (cutãs de iluviação);

3- Os fenômenos de degradação (desmantelamento, descoloração, estruturação plásmica) relatados ocorrem predominantemente no topo e na base das bandas onduladas e do $\mathrm{Bt}$, revelando uma dinâmica de formação e destruição dessas feições e do horizonte Eb. 
OLIVEIRA, D. de. As bandas onduladas e sua influência na evolução do...

\section{Interpretações e considerações finais}

A transformação dos Neossolos Quartzarênicos em Neossolos Quartzarênicos intermediários para Argissolo Vermelho-Amarelo e destes para Argissolo Vermelho-Amarelo dáse por processos pedogenéticos de translocação de argila.

A dissociação plasma/esqueleto resulta na migração da argila seguida da sua acumulação vertical e lateral e numa concentração residual do esqueleto, que progressivamente torna-se mais e mais lavado, à medida que a argila migra.

A presença de cutãs orientados formando pontes entre os grãos, preenchendo poros ou envolvendo grãos, além da cerosidade em campo são as feições que testemunham a translocação da argila.

Tais feições foram encontradas tanto em campo como nas lâminas delgadas, de modo que se trata de um processo de eiluviação, tanto nos Neossolos Quartzarênicos como no Argissolo, representativos dos segmentos superior e médio da vertente.

No sistema e-iluvial observa-se que a separação do esqueleto e do plasma caulinítico-ferruginoso, influenciada pela circulação hídrica, promove a exportação do plasma em profundidade e no rumo jusante, onde se acumula. Isso faz com que a drenagem interna torne-se cada vez mais interrompida para jusante pela diminuição da porosidade e aumento do plasma e também acarrete mudanças na estrutura, que passa de maciça muito friável nos Neossolos Quartzarênicos a poliédrica no Bt pela expansão/retração dos materiais. A presença de quantidades consideráveis de areia (maiores que 75\%) é também um importante indicador de uma porosidade funcional que irá auxiliar na translocação das argilas, mesmo que em pequenas quantidades (menores que 15\% nos Neossolos Quartzarênicos).

A formação das bandas onduladas no interior dos Neossolos Quartzarênicos é facilitada pela ação da gravidade e peneiramento na porosidade de empilhamento, através do fluxo de água, que carrega partículas em suspensão formando uma banda incipiente, que acaba sendo uma barreira para o movimento da água descendente, dado o entupimento dos poros de baixo para cima. Isto acarreta translocações 
OLIVEIRA, D. de. As bandas onduladas e sua influência na evolução do...

sucessivas ao longo do perfil, graças às condições de clima tropical com estações alternadas presentes na área.

Portanto, a Topossequência Retiro I corresponde ao sistema pedológico da borda montante do interflúvio Ribeirão do Meio/Samambaia e mostra-se ainda em atividade de transformação pedológica lateral dos Neossolos Quartzarênicos com bandas onduladas em Argissolo pouco desenvolvido.

Os segmentos superior e médio da topossequência constituem um sistema de transformação pedológica ligado à gênese das bandas onduladas e do $\mathrm{Bt}$ da transição glacis-zona dissecada.

Estes solos são, portanto, os primeiros indicadores de uma evolução morfopedogenética regressiva do glacis em direção à cuesta e resultante de dissecação pela rede de drenagem. A intensificação do entalhamento do glacis, hoje desfeito em interflúvios menores, pode estar relacionada à umidificação progressiva do clima que se seguiu durante todo o Quaternário (após a fase seca inicial Plio-Pleistocênica), ainda hoje atuante, mas que não teria arrasado totalmente o glacis, já que parte considerável da sua superfície encontra-se ainda pouco dissecada, portanto relativamente conservada.

\section{Referências bibliográficas}

ALMEIDA, F. F. M. de Fundamentos geológicos do relevo paulista. Geologia do Estado de São Paulo. São Paulo, Instituto Geográfico e Geológico, (41):167-263, 1964.

BOND, W. J. Illuvial band formation in a laboratory column of sand. Soil Sci. Soc. Am. J., Madison, 50(2): 265-267, 1986.

BOULET, R.; CHAUVEL, A.; HUMBEL, F. X. \& LUCAS, Y. Analyse structurale et cartographie en Pédologie. I - Prise en compte de l'organisation bidimensionnalle de la couverture pédologique: les études de toposéquences et leurs principaux apport à la connaisance des sols. Cah. ORSTOM Série Pédologie, Vol. XIX, n 4, p. 309-322, 1982. 
OLIVEIRA, D. de. As bandas onduladas e sua influência na evolução do...

BOULET, R.; HUMBEL. F. X.\& LUCAS. Y. Analyse structurale et cartografie en Pédologie. II - Une méthode d'analyse prenant en compte l'organisation tridimensionnelle des couvertures pédologiques.

Cah. ORSTOM Série Pédologie, Vol. XIX, nº 4, p. 323-340, 1982.

BOULET, R.; HUMBEL, F. X. \& LUCAS Y. Analyse structurale et cartographie en Pédologie. III - Passage de la analytique à une cartographie génerale synthétique. Cah. ORSTOM Série Pédologie, Vol. XIX, n 4, p. 341-352, 1982.

BREWER, R. Fabric and mineral analysis of soils. New York: Willy, 470p, 1964.

CAPELLARI, B. Estudo das áreas de risco à erosão em São Pedro, SP. São Paulo. (Trabalho de Graduação Individual), Departamento de Geografia-FFLCH-USP, 1996.

COUTARD, J. P.; DIAS FERREIRA, R. P.; PELLERIN, J. \& QUEIROZ NETO, J. P. Excursão à região da Serra de São Pedro e Vale do rio Piracicaba in: Guia das Excursões vol. II do Colóquio Interdisciplinar Franco-Brasileiro: Estudo e Cartografia de Formações Superficiais e suas aplicações em regiões tropicais, São Paulo, p. 45-74, 1978.

DIJKERMAN, J. C.; CLINE, M.G. \& OLSON, G.W. Properties and genesis of textural subsoil lamellae. Soil Sci., 104: 7-16, 1967.

LEMOS, R. C. \& SANTOS, R. D. Manual de descrição e coleta de solo no campo. Campinas: SBCS, 45p, 1982.

OLIVEIRA, D. de Estudo da origem dos materiais dos solos da cobertura arenosa do glacis de São Pedro, em São Pedro, SP. São Paulo, 75 p. (Trabalho de Graduação Individual), Departamento de Geografia-FFLCH-USP, 1992.

OLIVEIRA, D. de Estudo macro e micromorfológico de uma topossequiência na bacia do Córrego do Retiro em São Pedro SP. São Paulo, 143p. (Dissertação de Mestrado), Departamento de Geografia-FFLCH-USP, 1997. 
OLIVEIRA, D. de. As bandas onduladas e sua influência na evolução do...

OLIVEIRA, J. B. \& van den BERG, M. Application of the soter methodology to a semi-detailed survey $(1: 100,000)$ in the Piracicaba region. ISRIC, SOTER, 28p, 1992.

QUEIROZ NETO, J. P. \& JOURNAUX, A. Carta geomorfológica de São Pedro-SP - Memorial Explicativo. IGUSP, São Paulo, (escala 1:50.000), 1978.

RAWLLING, J. E. A review of lamellae. Geomorphology, 35, 19, 2000.

RUELLAN, A. \& DOSSO, M. Regards sur le sol. Universités Francophones. Édicion Soucher, Paris, 192 p., 1993.

STOOPS, G. \& JONGERIUS, A. Proposal for micromorphological classification in soil materials. I. A classification of related distribuitions of coarse and fine particles. Geoderma, Amsterdam, 13:p.189-200. (a reply Geoderma, 19, p.247-249, 1977), 1975.

SUGUIO. K. \& COIMBRA, A. M. Estudo sedimentológico das bandas onduladas de solos da formação Bauru na área balisada pelas cidades de Osvaldo Cruz - Rancharia e Tupã, Estado de São Paulo. Boletim do Instituto de Geociências. IG-USP. São Paulo, 7: 27-38, 1976.

WU, F. T. \& SOARES, P. C. Minerais pesados nas formações Pirambóia e Botucatu, Anais do XXVIII Congresso Brasileiro de Geologia, Porto Alegre, vol. 2, p. 119-127, 1974.

Parte da Dissertação de Mestrado desenvolvida no Departamento de Geografia da USP, sob orientação da Profa. Dra. Selma Simões de Castro e financiada pela FAPESP (Fundação de Amparo à Pesquisa do Estado de São Paulo). 